\title{
Poe en España: las primeras influencias
}

\author{
Juan Molina Porras*
}

\section{Resumen:}

Este trabajo explora la poco estudiada y muchas veces desatendida recepción e influencia que Edgar Allan Poe ejerció sobre los escritores españoles del siglo XIX y principios del XX y su importancia para la generación de lo fantástico en una literatura española que, en general, deja fuera de su canon esta faceta. El escritor norteamericano fue una presencia que obsesionó (obsesiona) a muchos autores y esa huella se ve en las improntas dejadas en los cuentos y temáticas y se hace presente en las traducciones y artículos que publicaron escritores como Pedro Antonio de Alarcón, Rafael Serrano Alcázar, Emilia Pardo Bazán y Pío Baroja. La idea que sustenta el trabajo no sólo atañe a la influencia de Poe, que se hace más importante a partir de la década de 1880 e impulsa la llegada a la imprenta de algunos de los mejores cuentos fantásticos españoles; señala también que en los últimos años del siglo XIX, el estilo y la escuela de Poe se confundieron y mezclaron con las de Maupassant dando así la entrada a la identidad de lo fantástico en España.

\section{Palabras clave:}

Literatura fantástica española, influencia de Poe, cuento español del 98, influencia de Maupassant, prensa literaria del siglo XIX.

Los que en los años setenta leímos por primera vez los cuentos de Poe en la magnífica de traducción de Cortázar pudimos, ingenua y tontamente, creer que éramos los primeros españoles que descubríamos la narrativa breve del narrador norteamericano. Nada más

\footnotetext{
${ }^{*}$ IES Murillo Sevilla.
} 
lejos de la realidad. La irrupción de la literatura sudamericana del boom en la cerrada España de los 60 y 70 pudo potenciar, entre otras cosas, una relectura y una actualización de la obra del cuentista norteamericano, pero las influencias venían de muy lejos. La que se deja sentir en el autor de Rayuela está al final de un ciclo que se inició prácticamente en el mismo instante en el que Baudelaire tradujo a Poe al francés. En efecto, Pedro Antonio de Alarcón el 18 de agosto de 1858 publicaba en las páginas de La Época el primer artículo en el que un español muestra interés por el autor de El gato negro: "Edgar Poe. Carta a un amigo". "Este interés no decreció en las décadas que restaban del XIX y podemos afirmar grosso modo que fue el autor que más influyó en la literatura fantástica española de la segunda mitad del siglo. Su obra sirvió para buscar otro tipo de verosimilitud y para contrarrestar la parafernalia imaginativa ligada a la corriente romántica. Si la primera mitad del siglo se había inquietado con las apariciones diabólicas, con los muertos vivientes, con las estatuas parlantes, con los fantasmas o con los aquelarres, los seguidores españoles de Poe pusieron coto, poco a poco, a esa imaginería ligada a la conseja y al cuento popular. Muy claro lo expresaba Alarcón cuando en sus Juicios literarios y artísticos afirmaba que "Edgar Poe no es nada de esto; ni el corazón ni la imaginación son su teatro; no es fantaseador ni místico; es naturalista, es sabio, es matemático. Quiere decir que su campo de batalla es la inteligencia [...] lo que siempre sirvió para combatir todo tipo de fantasmas" (Juicios 109). Más adelante se atreve a afirmar que la razón es su aliada en la construcción de relatos en los que emerge lo imposible, lo extraordinario o lo inverosímil. La fantasía y el terror, que se irán imponiendo tras la lectura alarconiana, serán distintos de los que habían triunfado en la primera mitad del siglo. Paradójicamente el Poe que sirvió a Cortazar para abrir nuevos caminos a la literatura fantástica, había sido también entrevisto como un aliado por los realistas españoles del XIX cuando éstos luchaban contra los

${ }^{1}$ Alarcón había leído los cuentos de Poe en su traducción francesa, Histories extraordinaires, y sigue en su ensayo las ideas que allí había expuesto Baudelaire. 
tópicos establecidos por el Romanticismo. Las líneas que siguen son un intento de historiar sintéticamente aquella pacífica y decimonónica batalla.

Como he indicado antes, el primer narrador español que reconoció la importancia de los cuentos del norteamericano fue Alarcón. En la Historia de mis libros declara que tres son las etapas que advierte en el desarrollo de su propia narrativa breve. Sobre las dos primeras planean las sombras de Scot, Dumas, Hugo y el extravagante y hoy olvidado Alfonso Karr. La tercera y última se caracteriza por estar más cerca de los presupuestos del Realismo y por hacer aflorar lo fantástico en contextos cotidianos. La lectura de Poe fue una ayuda inestimable en esa transformación del cuento alarconiano. Significativamente el primer texto en el que su sombra está presente también vio la luz en 1858: en las páginas de El Museo Universal los lectores pudieron leer Los ojos negros, una de las narraciones de Alarcón más desaforadamente románticas. Como en otras ocasiones, caso de El final de Norma o de El año en Spitz̧berg, la narración se traslada a frías regiones nórdicas. En su desarrollo conoceremos que la esposa del señor del castillo, la jarlesa Roedora, le ha sido infiel con un marino español. Los ojos de este último, para no huir del tópico, son negros como sugería el título. La violencia del marido, Magno de Kimi, estalla cuando conoce que el hijo de su esposa también tiene los ojos de ese mismo color y esa será la causa de que los tres últimos capítulos se centren en la descripción del duelo entre Magno y Alfonso de Haro, nombre del marino. En alta mar su lucha es interrumpida por el Maesltröm. El fantástico fenómeno pondrá fin a la vida de los dos contendientes.

El interés de este relato, que no logra superar las convenciones de la leyenda romántica, se halla en la primeriza y superficial influencia de Poe. Alarcón, pocas dudas caben, acaba de leer A Descent into Maesltröm y hace también aparecer el extraño y gigantesco remolino en su cuento. Pero, mientras que en la narración de Poe un personaje ha sobrevivido y nos cuenta en primera persona la tremenda experiencia de ser engullido por el Maesltröm, el poco verosímil narrador omnisciente de Los ojos negros relata la aparición del remolino como si de un castigo divino se tratase. Su inesperada 
entrada en la historia viene a poner fin a la insensata lucha entre dos hombres que se enfrentan por la posesión de una mujer. Los datos "científicos" que empleaba Poe no están presentes en Alarcón, que busca construir una narración legendaria lejana de cualquier atisbo de verosimilitud realista. En cualquier caso, con Carla Perugini hay que afirmar que es uno de los primeros cuentos en los que se advierte su influjo y una "probabile derivazione poesca dell' inabissamento nel vértice del Maesltrom” (130).

Muchos años después, Pedro Antonio de Alarcón ha asumido en profundidad las premisas estéticas del mejor $P_{0 e}^{2}$ y escribe $L a$ mujer alta. Esta narración, fechada en agosto de 1881 y aparecida en La Ilustración Artística en 1882, es un claro ejemplo de que ha asimilado los supuestos estéticos que, en el lejano 1858, Alarcón advertía en Poe. Todo aquí es razonable y verosímil. La historia se desarrolla en una ciudad real, Madrid; ocurre en el momento histórico en el que viven los lectores, la segunda mitad del xix, y el ambiente es caracterizado con mil y un detalles por el narrador. Estamos muy lejos de los exóticos mundos medievales y de las sombrías penumbras góticas en los que se desenvolvían las leyendas románticas. El creador de este relato sabe que el horror debe surgir en medio de la vida cotidiana y acepta todas las convenciones que exige el clima ideológico y cultural dominado por el Positivismo y el Realismo. El suceso extranatural, además, sólo es entrevisto como una posibilidad por alguno de los narradores de la historia. En este sentido, hay que recordar que en La mujer alta la aparición de esa extraña mujer coincide siempre con una muerte inminente. No hay ningún otro fenómeno extraño. Como en El corazón delator o El gato negro la probabilidad de que estemos ante un suceso que viole las reglas naturales sólo es admitido por un narrador inmerso en la propia historia. En nuestro caso, y como en los relatos citados, no sería nada extraño que estuviera enloqueciendo o, al menos, padezca una crisis

\footnotetext{
${ }^{2}$ Alarcón en su análisis de los cuentos de Poe se fija en los aspectos, digámoslo así, más racionales y lógicos, pero es indudable que en éste hay muchos elementos que aún son deudores de los relatos góticos.
} 
nerviosa. Así lo constatan sus miedos o las interrogaciones que se hace cuando encuentra a la extraña mujer: “ ¿Es mujer? ¿Es criatura humana? ¿Por qué la he presentido desde que nací? ¿Por qué me reconoció al verme? ¿Por qué se me presenta sino cuando me ha sucedido una desgracia? ¿Es Satanás? ¿Es la Muerte? ¿Es la Vida? ¿Es Anticristo? ¿Quién es? Qué es?... (Novelas 141). Las excitadas palabras reflejan las enseñanzas de Poe. Si lo fantástico romántico se suele asociar al sueño o a lo onírico, en la segunda mitad aflorará de los labios de un narrador o en los ojos de un focalizador que sufren alteraciones psíquicas. No puedo desarrollar en profundidad la idea, pero es evidente que los lectores de las tres décadas finales del XIX parecen haberse aburrido de que las fantasías y los terrores encuentren una justificación onírica. En esta época la preferencia naturalista por el personaje marginal o por el loco triunfa también en el campo de la literatura fantástica. La alianza de la locura y lo sobrenatural será un elemento decisivo para alterar las convenciones establecidas. Si lo sobrenatural es sólo una posibilidad para el descreído hombre contemporáneo, adoptar un punto de vista narrativo desde la perspectiva de un ser alienado sirve también para dar visos de verosimilitud al relato.

La vía abierta en 1858 por Alarcón fue pronto seguida por otros creadores. Rodríguez Guerrero-Strachan en el único libro dedicado al tema que desarrollamos, Presencia de Edgar Allan Poe en la literatura española del siglo XIX, se atreve a afirmar, a mi entender de forma poco convincente, que Galdós o Clarín sufrieron su influjo directo. Sin embargo, olvida o dedica poco espacio a otros cuentistas hoy casi olvidados cuya producción no se puede entender sin la de aquél. Rafael Serrano Alcázar, autor de Cuentos negros o historias extravagantes, es uno de los primeros en seguir la estela iniciada por Alarcón. Esta estimable y variopinta colección de relatos es posible que tuviera tres ediciones en la década de los $70 \mathrm{y}$, como era habitual en la época, que recogiera textos aparecidos antes en diversas revistas. El autor, defendiéndose de posibles ataques críticos, se pregunta en el prólogo si sus obras “¿tendrán relación con las Historias extraordinarias de Poe?” Más adelante se defiende afirmando que "lo ignoro, pero afirmo que cuando publiqué las primeras de las mías 
yo no había leído a Poe" (xx). Las palabras de Serrano Alcázar son prueba fehaciente de que en los años setenta Poe era un escritor popular y conocido. Por oto lado, podemos creer que la ambigua respuesta es sincera y responde a la realidad. En efecto, la colección contiene narraciones legendarias que poca relación guardan con el autor del que hablamos. Es el caso de El árbol de Iphigenia, historia enclavada en ambientes germánicos que, si la lógica primara, habría sido creada antes que El cuervo blanco. En este último caso ni el título ni la trama policíaca pueden ser simples coincidencias. En resumen, podemos creer que Serrano Alcázar escribió algunos cuentos siguiendo a Poe, pero también es indudable que otros de la colección nada tienen que ver con él. En cualquier caso, si realmente existe una edición de 1872, quizá sea, tras Alarcón, el segundo autor español que recibió las enseñanzas de Poe. Lo atestigua El cuervo blanco, que junto con el alarconiano El clavo, se constituiría como una de las primeras manifestaciones del cuento policial en España.

En él un pastor ve cómo un pájaro ahonda con su pico en un muladar. Al remover la tierra encuentra cuatro cabezas humanas desprovistas de tronco. Tres vulgares cazadores, calificados para crear verosimilitud con las letras X, R y Q, son acusados del crimen y más tarde ajusticiados. Pero un cabo falta en la historia: los cuerpos de las víctimas. Se realizan prácticas de hechicería y una vieja gitana predice que un cuervo enseñará el camino de la verdad. Al final, la justicia tendrá que reconocer que ha cometido un trágico error y sabremos que los asesinatos tiene su origen en un rocambolesco crimen pasional. El relato podría apuntar la presencia de algún elemento sobrenatural encarnado aquí en las figuras de la vieja gitana y el cuervo blanco. De la primera el narrador da la suficiente información para que deduzcamos que sólo se trata de una mujer muy lista y que la hechicería es su medio de vida. El cuervo, que podría ser un agente de la justicia ultraterrena, parece

${ }^{3}$ Según la Enciclopedia Espasa existe una edición de 1872. David Roas habla de otra aparecida en Albacete y editada por Estudio Tipográfico de Sebastián en 1874. La misma fecha dan Ferreras y Baquero Goyanes. Por mi parte he podido consultar en la Biblioteca Nacional una edición de 1878. 
seguir su naturaleza y, por eso, será el que descubra finalmente los decapitados cuerpos de los asesinados. Sin embargo, lo sobrenatural, como en los cuentos policiales del norteamericano, cumple la función de ofrecer falsas pistas al lector. Estas obras huyen siempre de soluciones de ese tipo, eliminan la posibilidad de lo sobrenatural y sólo pueden proponer una conclusión que no viole la lógica natural. En otras palabras, lo fantástico se haya excluido del género.

En la década de los ochenta el rastro de Poe vuelve a estar presente en el primer libro de cuentos de Silverio Lanza, El año triste. El que inicia la colección, Año nuevo, es una muestra, junto con $L a$ mijer alta, de que su narrativa espolea a otros creadores a presentar el mundo desde los ojos del asesino o del alienado. En esta ocasión la narración se presenta bajo la forma de una corta y alucinada carta que un tal Jorge envía a un amigo desde El Ferrol. La fábula y la historia son mínimas: Jorge y su esposa, aislados en el campo, necesitan un médico cuando ella dé a luz. Él va a buscarlo a la ciudad. A la vuelta madre e hijo han muerto y su suegro lo tacha de asesino. Desesperado inicia una inútil huida: "Comprendí que me seguían para cogerme, y corrí, corrí sin descanso, porque tenía miedo, $\mathrm{Pa}-$ blo, mucho miedo. Vagué por el campo toda la noche, y, a la mañana siguiente atravesé El Ferrol, llamando la atención de la gente" (42). Finaliza la misiva indicando que le han dado el retiro y que todos lo consideran culpable. El interés del relato reside en el punto de vista narrativo adoptado: el de un personaje cargado de remordimientos y culpas. No es Año nuevo un cuento fantástico ni tampoco maravilloso pero el lector se siente preso de la extrañeza propia de los relatos fantásticos del siglo xx. Ese sentimiento emerge al percibir algo anormal en la mente del narrador no de la irrupción de un agente sobrenatural. En esa misma línea se hallan algunas narraciones de Emilia Pardo Bazán.

En la ingente producción de la novelista gallega (llegó a publicar más de seiscientos cuentos) no podían faltar los de raíz poesca. El caso más evidente se encuentra en El espectro. ${ }^{4}$ El desequilibrado protagonista no siente aversión hacia los gatos negros sino hacia

${ }^{4}$ Aparecido en La Ilustración Española y Americana, no 4 (1909). 
los blancos. La contemplación de uno le hará rememorar el desgraciado día en que confundió el pañuelo de su madre con uno de esos animales. Si en El gato negro el narrador descarga su violencia contra su mujer, en este caso Lucio lo hace contra su madre. Las interpretaciones freudianas de la historia son tan fáciles y las concomitancias con el modelo tan evidentes que el lector acaba por dar poco crédito a la historia que le cuenta doña Emilia. Quizá, lo más interesante de su producción fantástica se halle en los relatos en los que sigue a Maupassant. Entre éstos cabe destacar dos: Eximente y Tiempo de ánimas. El primero guarda un parecido evidente con El horla y el segundo con Auprés d'un mort. Aunque ambos tienen claras relaciones con la narrativa breve del naturalista francés, debo hacer notar que son eslabones de la cadena que se inició en Poe. No es El horla el primer cuento en el que lo fantástico se ha revestido de un ropaje psicológico, aunque sí uno de sus frutos más logrados. El terror presente en El corazón delator o en El gato negro sólo encuentra su explicación en la introspección que realiza el norteamericano en unas mentes asesinas que declaran estar poseídas por brujas o por la mirada diabólica de un viejo. Esa tradición fue retomada por Maupassant y a través de él pasó a Emilia Pardo Bazán.

En los albores del nuevo siglo doña Emilia no está sola porque Médium es otra muestra de este tipo de relatos. De nuevo Poe y Maupassant se dan la mano en el citado cuento de Baroja. Su inicio es casi un calco de El gato negro: "Soy un hombre intranquilo, nervioso, muy nervioso; pero no estoy loco, como dicen los médicos que me han reconocido" (31). Como en El horla la locura del personaje de la narración barojiana puede ser una señal de que algo sobrenatural se ha apoderado de su mente. Aunque también es posible que sólo sea un caso de simple alienación. En todo caso el cuento barojiano testimonia que la influencia de Poe entraba con buen pie en el siglo xx.

Llegado a este punto es fácil concluir que, si bien sus cuentos fueron rápidamente conocidos a partir de su traducción francesa, su influencia fue bastante superficial hasta bien entrada la década de los setenta. Es posible pensar que sólo en la década de los ochenta algunos narradores habían asumido en profundidad sus enseñanzas 
y es el momento en el que dieron a la imprenta algunos de los mejores cuentos fantásticos españoles. En los últimos años del siglo, éstas se confundieron y mezclaron con las de Maupassant. En cualquier caso, debo apuntar que este aspecto de nuestra literatura ha sido poco estudiado y que merecería más atención porque es un testimonio de que lo fantástico, en contra de lo que afirman los tópicos noventayochistas, es un faceta más de la literatura en castellano.

\section{Obras citadas}

Alarcón, Pedro Antonio. Novelas cortas de Pedro Antonio de Alarcón.

Narraciones inverosimiles. Madrid: Imprenta y Fundición de Tello, 1882.

- El capitán Veneno. Historia de mis libros. Madrid: Estudio Tipográfico Sucesores de Ribadeneyra, 1905.

1921.

. Juicios literarios y artísticos. Madrid: Sucesores de Ribadeneyra,

Baroja, Pío. Vidas sombrías. Madrid: Afrodisio Aguado, 1955.

Lanza, Silverio. Obras completas. I. El año triste. Madrid: Editorial Orígenes, 1989.

Pardo Bazán, Emilia. Cuentos completos. 4 vols. La Coruña: Fundación Pedro Barrie de la Maza, conde de Fenosa, 1990.

Perugini, Carla. "Il fantastico nella letteratura spagnola del secolo XIx.” Parti I e II. Studi Ispanici (Pisa) (1985 y 1987-1988): 97-123 y125-150.

Rodríguez Guerrero-Strachan, Santiago. Presencia de Poe en la literatura española del siglo XIX. Valladolid: Secretariado de Publicaciones e Intercambio científico de la Universidad de Valladolid, 1999.

Serrano Alcázar, Eusebio. Cuentos negros o historias extravagantes. Albacete: Estudio Tipográfico Sebastián Ruiz, 1878. 